\title{
PERAN TIM TENDER DALAM USAHA PERAIHAN NILAI KONTRAK PADA PERUSAHAAN JASA KONSTRUKSI
}

\begin{abstract}
Adhi Purnomo
Abstrak

Di dalam industri jasa konstruksi, khususnya kontraktor, proses perencanaan yang matang dalam pelaksanaan proyek mempunyai andil yang cukup besar menentukan kinerja proyek dan perusahaan itu sendiri. Tim Tender ini merupakan salah satu aktualisasi proses overlapping kegiatan pemasaran dan kegiatan produksi/operasi dalam industri jasa konstruksi, sedangkan output dari Tim Tender ini adalah Kontrak Konstruksi antara kontraktor dengan owner. Penelitian ini bertujuan mengetahui faktor-faktor yang mempengaruhi kinerja Tim Tender dalam melaksanakan kegiatan tender ketika mengikuti proses pelelangan.

Penelitian ini menggunakan analisis statistik untuk dapat mengetahui faktor-faktor yang mempengaruhi Tim Tender terhadap tingkat keberhasilan pelelangan.

Dari hasil pengolahan data didapatkan faktor kompetensi perusahaan dan ketersediaan sumber daya manusia yang merupakan faktor paling dominan terhadap tingkat keberhasilan Tim Tender dalam melaksanakan kegiatan tender khususnya pada tender yang bersifat kompetitif.
\end{abstract}

Kata kunci : Tim Tender, kontrak konstruksi, owner, tingkat keberhasilan

\section{Adhi Purnomo, MT}

Staff Pengajar Jurusan Teknik Sipil

Fakultas Teknik Universitas Negeri Jakarta

\section{PENDAHULUAN}

Pada dasarnya perencanaan strategi suatu perusahaan dalam menjalankan bisnisnya merujuk pada beberapa prosedur untuk mengembangkan dan mencapai sasaran bisnis tertentu yang telah ditentukan. Seperti kontraktor, perencanaan strategi perusahaan dalam persaingan industri jasa konstruksi mengutamakan penekanan pada identifikasi "seperti apakah" suatu proyek bisa dilakukan penawaran dan "bagaimana" menawarkan harga untuk proyek tersebut (Park, William R.; 1979). 
Dalam manajemen strategi industri manufaktur, manajemen organisasinya difokuskan pada kelangsungan jangka panjang suatu produk yang dihasilkan, sedangkan dalam industri jasa konstruksi umumnya difokuskan pada suatu produksi dan hasil akhir produk yang unik (Chinowsky, Paul S.; 2001), sehingga konsep manajemen strategi dalam industri jasa konstruksi adalah :

- Visi, misi, dan tujuan

Merupakan titik awal untuk semua organisasi usaha, karena dalam visi, misi, dan tujuan menguraikan setiap kegiatan sesuai dengan praktek usaha yang dilaksanakannya.

- Kompetensi utama

Merupakan suatu batasan usaha untuk suatu organisasi. Kompetensi utama ini ditentukan dari kemampuan terbaik dari suatu organisasi untuk melaksanakan kegiatan usahanya dan kekuatan organisasi itu sendiri.

- IImu pengetahuan

Kombinasi dari sumber daya manusia dan teknologi yang mampu disediakan oleh organisasi yang menjadi tulang punggung untuk organisasi dalam menyelesaikan suatu proyek.

- Pelatihan

Difokuskan pada pengembangan informal dan formal untuk jangka panjang dan peningkatan kondisi usaha.

- Keuangan

Lingkup yang luas adalah kondisi moneter diluar pelaksanaan proyek dan juga diutamakan pada pengendalian biaya dan schedule pelaksanaan proyek.

- Pasar

Analisa pengembangan kesempatan usaha dalam wilayah yang berhubungan dengan kompetensi utama.

- Kompetisi

Difokuskan pada analisa dan pengertian mengenai kondisi yang ada, dan kompetitor di masa depan pada segmen pasar potensialnya.

Kontraktor Jasa Konstruksi sebagai Pelaksana Konstruksi didefinisikan sebagai penyedia jasa orang perseorangan atau badan usaha yang dinyatakan ahli, profesional di bidang pelaksanaan jasa konstruksi, yang mampu menyelenggarakan kegiatannya untuk mewujudkan suatu hasil perencanaan menjadi bentuk bangunan atau bentuk fisik lainnya dan terikat kontrak untuk menyelesaikan pekerjaan konstruksi (PP; 2003). 
Kegiatan pemasaran merupakan kegiatan awal sebelum kegiatan produksi atau pelaksanaan proyek dilaksanakan. Sasaran kegiatan pemasaran adalah pendekatan kepada Pelanggan/Konsumen dengan Direct Marketing (kontak langsung dengan calon Pelanggan). Pada dasarnya kegiatan pemasaran sendiri dibagi menjadi 3 (tiga) tahap (Asiyanto; 2006) :

- Market Research

- Direct Marketing Program

- Market Result

\section{Sederhana}

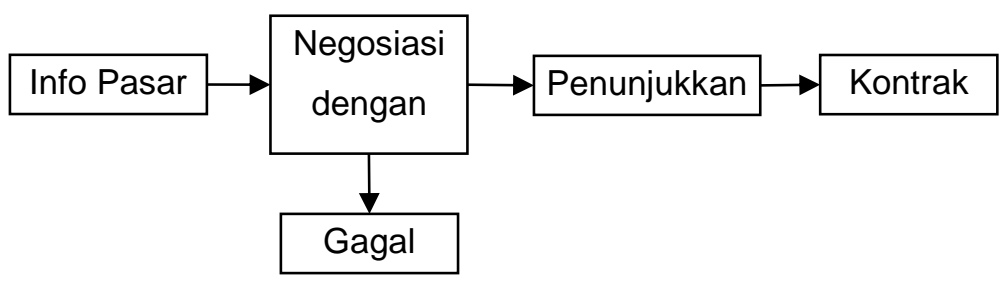

\section{Sedang}

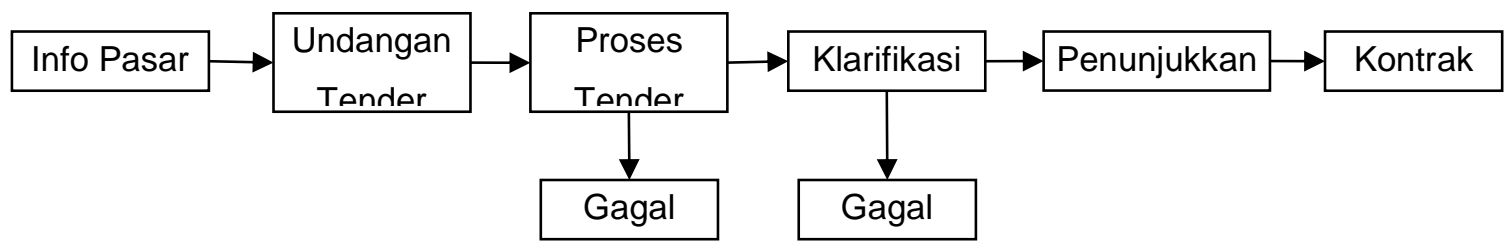

\section{Berat}

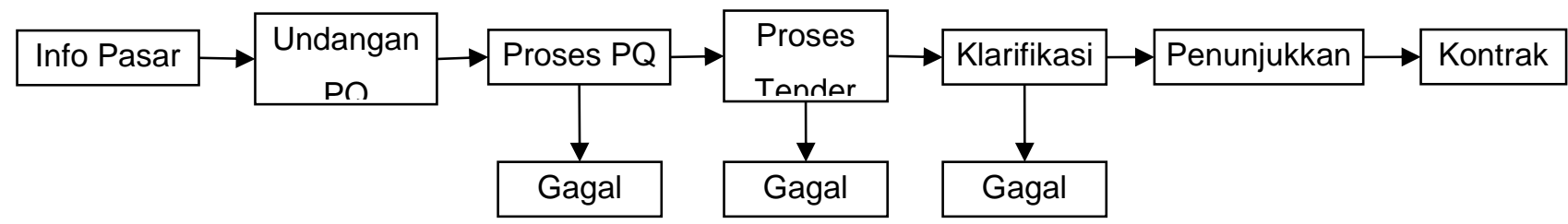

Sumber : Asiyanto, 2006

Gambar 1. Tingkatan proses perolehan kontrak

Yang dimaksud dengan Market Research adalah semua tindakan dan upaya untuk memperoleh informasi tentang proyek konstruksi yang ada, dan yang dapat dikembangkan menjadi pasar konstruksi melalui ide pengajuan proposal. Dalam menggali informasi, diusahakan agar sampai pada sumber informasi yang paling hulu. Kemudian informasi tersebut ditindaklanjuti dengan pendekatanpendekatan kepada Owner, Konsultan, Rekanan atau bila memungkinkan pada siapapun yang memiliki power untuk mempengaruhi pasar. Semua kegiatan pemasaran, harus dibuat perencanaannya dan juga dibuat laporan pelaksanaannya secara berkala. Kegiatan pemasaran tersebut tidak selalu berakhir 
dengan "market resulf" berupa kontrak konstruksi, namun demikian proses berjalannya kegiatan tersebut perlu untuk bahan evaluasi. Bila kondisi persaingan ketat atau kurang fair, maka perlu dilakukan kegiatan "market intelegence", yang pada dasarnya untuk melawan pesaing yang potensial (Asiyanto; 2006). Berikut ini adalah 3 (tiga) tingkatan proses perolehan kontrak, terlihat pada gambar 1.

Menurut Keppres No. 80 Tahun 2003, metode Evaluasi Penawaran dalam proses pelelangan untuk Pengadaan Barang/Jasa Pemborongan/Jasa Lainnya adalah : Sistem Gugur, Sistem Nilai (Merit Point System), dan Sistem Penilaian Biaya Selama Umur Ekonomis (Economic Life Cycle Cost).

Kelangsungan hidup dari kontraktor sangat ditentukan dari target perolehan kontrak yang bisa dicapai. Secara umum ada dua strategi dari kontraktor untuk memenangkan tender (Asiyanto, 2005) :

* Strategi kompetitif (competitive strategy)

* Strategi persengkokolan (bid rigging strategy)

Waktu yang diperlukan untuk menyelesaikan suatu proyek sangat bervariasi, bergantung pada besar kecilnya proyek atau tingkat kesulitannya. Namun demikian, proyek selalu memiliki 4 (empat) tahapan, yaitu (Asiyanto; 2005) :

- Tahapan Evaluation and Planning

- Tahapan Conceptual Engineering

- Tahapan Detailed Engineering

- Tahapan Construction

Dalam tahapan-tahapan tersebut, ada 3 (tiga) macam cost estimate proyek yang diperlukan pada saat yang bersangkutan, yaitu (Asiyanto; 2006) :

- Preliminary Estimate (PE)

Cost estimate ini ada pada tahap planning. Pada tahap ini desain proyek belum ada, tetapi baru ada dalam bentuk gagasan. Namun demikian cost estimate sudah harus diberikan untuk keperluan analisis studi kelayakan. Pada tahap ini biaya proyek (cost estimate) dihitung secara kasar (global), berdasarkan informasi harga dari proyek sejenis persatuan kapasitas produksi, atau per satuan fungsinya, atau per satuan luasnya.

- Semi Detailed Estimate (SE)

Cost estimate ini ada pada tahap conceptual engineering. Pada tahap ini basic design proyek sudah ada, sehingga cost estimate proyek sudah dapat dihitung agak detail berdasarkan perkiraan quantity pekerjaan dan informasi harga satuan pekerjaan pada saat yang bersangkutan. Pada 
tahap ini, cost estimate biasanya belum dihitung berdasarkan construction method yang spesifik. Dan biasanya hanya diperlukan sebagai dasar pertimbangan untuk menyiapkan dana yang diperlukan bagi proyek tersebut, oleh karena itu sering juga disebut sebagai budget estimate bagi owner.

- Definitive Estimate (DE)

Cost estimate ini ada pada tahap detailed engineering, dengan semua informasi yang diperlukan untuk pelaksanaan sudah lengkap. Pada tahap ini construction drawing sudah ada, sehingga estimasi biaya dapat dihitung secara detail. Pada tahap ini, awalnya ada dua estimasi untuk fisik bangunan, yaitu versi owner, yang sering disebut dengan Owner Estimate (OE), dan versi kontraktor, yang disebut sebagai Bid Price (harga penawaran).

Suatu cost estimate tidak hanya menampilkan biaya proyek saja, namun juga menyeimbangkan kewajiban dalam pengawasan biaya selama pelaksanaan proyek. Hal ini dikarenakan hubungan antara estimasi biaya, schedule pelaksanaan, dan pengendalian biaya (cost control) sangatlah penting, dimana identifikasi biaya harus sudah dilakukan oleh cost engineer, sehingga akan terwujud anggaran biaya proyek yang efektif. Oleh karena itu, estimasi biaya yang efektif tidak hanya menampilkan biaya yang realistis, namun juga menampilkan informasi yang akurat dengan merujuk pada schedule pelaksanaan, pengendalian biaya, dan kemajuan progress selama proses pelaksanaan (Dysert, Larry dan Elliot, Bruce G.;2002).

Dalam menyusun construction cost estimate, walaupun sebagai nilai yang diperkirakan, tetapi tetap menggunakan faktor kunci yang pasti (Asiyanto; 2005), yaitu antara lain :

- Construction schedule

- Construction technology (construction method)

- Dasar produktivitas tenaga kerja

- Metode estimasi

Tim Tender dari kontraktor menjadi aktualisasi dari overlapping bagian pemasaran dan produksi yang dibentuk oleh manajemen perusahaan. Berikut ini adalah beberapa lingkup pekerjaan yang harus dilaksanakan oleh Tim Tender selama mengikuti proses pelelangan (PP, 2003) yaitu :

1. Melakukan penyusunan dokumen administrasi lelang sesuai persyaratan atau kualifikasi dalam dokumen pengadaan dan kemampuan perusahaan seperti : 
a. Data perusahaan, meliputi :

- Nama perusahaan.

- Alamat, telepon, faksimile, email.

- Pendirian perusahaan.

- Susunan direksi.

- Jumlah karyawan tetap (manajer, staf teknik, staf administrasi)

b. Kinerja dalam proyek yang sama termasuk referensi terdahulu, mencakup :

- Jenis proyek.

- Pemilik proyek.

- Nama proyek dan lokasi.

- Tahun pelaksanaan.

- Posisi dalam kontrak proyek tersebut (sebagai kontraktor utama atau sub kontraktor).

- Nilai kontrak (rupiah atau equivalent rupiah).

c. Daftar pengalaman proyek pada lima tahun terakhir dilengkapi dengan personil yang menangani.

d. Sumber daya manusia yang direncanakan menangani proyek, dilengkapi :

- Struktur organisasi proyek.

- Nama personil, posisi, umur, pengalaman kerja.

e. Kemampuan penyediaan peralatan, meliputi :

- Tipe alat.

- Jumlah.

- Kapasitas operasi.

- Tahun pembuatan alat.

- Status kepemilikan.

f. Kemampuan keuangan, meliputi :

- Balance sheet (neraca) tiga tahun terakhir.

- Current asset pada enam bulan terakhir.

- Certificate of time deposit selama enam bulan terakhir.

- Credit line certificate.

- Letter of guarantee (surat jaminan bank yang memberi dukungan khusus untuk proyek yang akan ditenderkan).

2. Melakukan penyusunan dokumen proposal teknik (technical proposal), seperti : 
a. Metode pelaksanaan (construction method).

b. Jadwal waktu pelaksanaan (time schedule).

c. Jadwal tenaga kerja (manpower schedule).

d. Jadwal alat (equipment schedule).

e. Jadwal bahan (material schedule).

f. Organisasi proyek dan personil (project organization and nominated personnel).

g. Daftar nama sub kontraktor yang diusulkan (list of proposed sub contractors).

3. Melakukan penyusunan estimasi penawaran harga atau proposal biaya (cost proposal), yang terdiri dari:

a. Surat penawaran (form of tender).

b. Perincian harga (proced bill of quantity).

C. Daftar harga satuan bahan.

d. Daftar harga satuan upah.

e. Analisa harga satuan (breakdown of unit price).

f. Jaminan tender (tender bond).

Dari uraian tugas-tugas Tim Tender diatas, dalam pelaksanaan kegiatan tender diperlukan keterlibatan personil yang berasal dari berbagai disiplin ilmu yang akan bekerja sesuai batas waktu yang terbatas. Oleh karena itu, Tim Tender yang dibentuk oleh manajemen (kontraktor) pada setiap proses tender seharusnya beranggotakan personil dari bagian pemasaran dan bagian produksi dengan tugas dan tanggung jawab masing-masing.

Dari uraian tugas Tim Tender diatas maka peran Tim Tender sangat besar dalam menentukan keberhasilan kinerja suatu proyek, walaupun kesuksesan suatu proyek masih diukur lagi dengan berbagai parameter yang lain. Ada beberapa parameter utama yang mempengaruhi peran Tim Tender pada saat melaksanakan proses penawaran harga. Identifikasi peran tim tender ini dibatasi pada proyek-proyek pelelangan yang diikuti, seperti (Hegazy, Tarek dan Moselhi, Osama; 1995) :

* Perkiraan lingkup pekerjaan (assessment of job complexity)

* Perkiraan kemampuan perusahaan (assessment of firm ability)

* Perkiraan kepastian pekerjaan (assessment of job uncertainty)

* Perkiraan pasar (assessment of market) 


\section{METODOLOGI}

Metode pengumpulan data yang dilakukan adalah dengan cara studi literatur dan survey pada sumber informasi yang dibutuhkan berupa wawancara terstruktur dan melalui kuesioner.

Data yang digunakan berupa data primer dan data sekunder. Data tersebut diperoleh dengan cara menyebarkan angket atau kuesioner dengan cara mewawancarai responden secara langsung terhadap pakar dalam bidang yang berkaitan dengan masalah yang dibahas.

\section{PEMBAHASAN}

Mengingat variabel-variabel bebas berjumlah cukup banyak, yakni 37 variabel, maka untuk mengurangi/mereduksi jumlah variabel tersebut dilakukan terlebih dahulu dengan menggunakan analisis AHP. sedangkan rangkuman hasil analisa AHP adalah sebagai berikut :

Tabel 1. Tabel analisa AHP

\begin{tabular}{|c|c|l|c|}
\hline No & Kode & \multicolumn{1}{|c|}{ Variabel } & Peringkat \\
\hline 1 & $X_{17}$ & Kompetensi Perusahaan & I \\
\hline 2 & $X_{13}$ & Ketersediaan Sumber Daya Manusia & II \\
\hline 3 & $X_{15}$ & Kemampuan Manajerial dan Supervisi & III \\
\hline 4 & $X_{25}$ & Kontraktor Yang Terlibat & IV \\
\hline 5 & $X_{14}$ & Pengalaman Proyek Sejenis & V \\
\hline 6 & $X_{18}$ & Kemampuan Keuangan & VI \\
\hline 7 & $X_{27}$ & Pengadaan Material & VII \\
\hline 8 & $X_{1}$ & Jenis Proyek & VIII \\
\hline 9 & $X_{8}$ & Sub Kontraktor & IX \\
\hline 10 & $X_{34}$ & Pertumbuhan Ekonomi & X \\
\hline 11 & $X_{26}$ & Stakeholder & XI \\
\hline 12 & $X_{28}$ & Pengadaan Peralatan & XII \\
\hline 13 & $X_{4}$ & Sumber Daya Manusia & XIII \\
\hline 14 & $X_{16}$ & Keinginan Untuk Bekerja & XIV \\
\hline 15 & $X_{19}$ & Target Nilai Kontrak & $\mathbf{X V I}$ \\
\hline 16 & $X_{9}$ & Cash Flow & \\
\hline 17 & $X_{33}$ & Paket Pekerjaan Lanjutan & XVI \\
\hline
\end{tabular}




\begin{tabular}{|c|c|l|c|}
\hline No & Kode & \multicolumn{1}{|c|}{ Variabel } & Peringkat \\
\hline 18 & $\mathrm{X}_{3}$ & Penggunaan Teknologi & $\mathbf{X V I I I}$ \\
\hline 19 & $\mathrm{X}_{12}$ & Cara Pembayaran & $\mathbf{X I X}$ \\
\hline 20 & $\mathrm{X}_{23}$ & Strategi & $\mathbf{X X}$ \\
\hline
\end{tabular}

Dari rangkuman hasil analisa proses AHP diatas menunjukkan bahwa variabel $\mathrm{X}_{17}$ (Kompetensi Perusahaan) merupakan faktor yang memegang peranan yang sangat tinggi terhadap peranan Tim Tender dalam melaksanakan kegiatan tender.

Sedangkan variabel $\mathrm{X}_{23}$ (Strategi) menempati peringkat paling bawah untuk faktor yang mempengaruhi Tim Tender. Dari hasil review tabulasi data menunjukkan bahwa responden dengan posisi manajer / kepala rata-rata menjawab bahwa variabel $\mathrm{X}_{23}$ (Strategi) sangat mempengaruhi tingkat keberhasilan Tim Tender dalam usaha memenangkan tender, namun untuk responden dengan posisi staf rata-rata berasumsikan bahwa strategi penawaran harga merupakan kebijakan dari top manajemen sehingga kegiatan Tim Tender belum mencakup analisis strateginya.

Dalam penelitian ini, analisis korelasi dilakukan untuk melihat peran Tim Tender dalam usaha meraih nilai kontrak pada perusahaan jasa kontruksi khususnya kontraktor.

Tabel 2. Hubungan antara Tim Tender terhadap Tingkat Keberhasilan (Y)

\begin{tabular}{|c|c|c|c|}
\hline \multirow{2}{*}{ No } & \multirow{2}{*}{ Kode } & \multirow{2}{*}{ Uraian } & r (Koefisien Korelasi) \\
\hline & & & $\mathbf{Y}$ \\
\hline 1 & $X_{1}$ & Jenis proyek & 0,090 \\
\hline 2 & $\mathrm{X}_{3}$ & Penggunaan teknologi & 0,077 \\
\hline 3 & $\mathrm{X}_{4}$ & Sumber daya manusia & 0,042 \\
\hline 4 & $\mathrm{X}_{8}$ & Sub Kontraktor & 0,148 \\
\hline 5 & $X_{9}$ & Cash flow & 0,215 \\
\hline 6 & $\mathrm{X}_{12}$ & Cara pembayaran & 0,277 \\
\hline 7 & $X_{13}$ & Ketersediaan sumber daya manusia & $0,352^{*}$ \\
\hline 8 & $X_{14}$ & Pengalaman proyek sejenis & 0,087 \\
\hline 9 & $\mathrm{X}_{15}$ & Kemampuan manajerial dan supervisi & $0,332^{*}$ \\
\hline 10 & $X_{16}$ & Keinginan untuk bekerja & 0,086 \\
\hline
\end{tabular}




\begin{tabular}{|c|c|l|c|}
\hline \multirow{2}{*}{ No } & \multirow{2}{*}{ Kode } & & $\mathbf{r}$ (Koefisien Korelasi) \\
\cline { 3 - 4 } & & & $\mathbf{Y}$ \\
\hline 11 & $\mathrm{X}_{17}$ & Kompetensi perusahaan & $0,460^{\text {** }}$ \\
\hline 12 & $\mathrm{X}_{18}$ & Kemampuan keuangan & 0,248 \\
\hline 13 & $\mathrm{X}_{19}$ & Target nilai kontrak & 0,080 \\
\hline 14 & $\mathrm{X}_{23}$ & Strategi & $0,335^{*}$ \\
\hline 15 & $\mathrm{X}_{25}$ & Kontraktor yang terlibat & 0,072 \\
\hline 16 & $\mathrm{X}_{26}$ & Stakeholder & 0,088 \\
\hline 17 & $\mathrm{X}_{27}$ & Pengadaan material & 0,107 \\
\hline 18 & $\mathrm{X}_{28}$ & Pengadaan peralatan & 0,044 \\
\hline 19 & $\mathrm{X}_{32}$ & Pemilik proyek & 0,295 \\
\hline 20 & $\mathrm{X}_{33}$ & Paket pekerjaan lanjutan & 0,147 \\
\hline
\end{tabular}

Sumber : Hasil Olahan

Setelah itu dilakukan eliminasi terhadap variabel yang tidak signifikan, maka didapatkan hasil seperti diperlihatkan pada tabel berikut ini,

Tabel 3. Koefisien Regresi Akhir Tingkat Keberhasilan

\begin{tabular}{|c|c|c|c|c|c|c|c|c|c|c|}
\hline & \multirow{2}{*}{ Model } & \multicolumn{2}{|c|}{$\begin{array}{l}\text { Unstandardized } \\
\text { Coefficients }\end{array}$} & \multirow{2}{*}{$\begin{array}{c}\begin{array}{c}\text { Standardized } \\
\text { Coefficients }\end{array} \\
\text { Beta }\end{array}$} & \multirow{2}{*}{$t$} & \multirow{2}{*}{ Sig } & \multicolumn{2}{|c|}{$\begin{array}{l}95 \% \text { Confidence } \\
\text { Interval for B }\end{array}$} & \multicolumn{2}{|c|}{ Collinearity Statistics } \\
\hline & & B & $\begin{array}{l}\text { Std. } \\
\text { Error }\end{array}$ & & & & $\begin{array}{l}\text { Lower } \\
\text { Bound }\end{array}$ & $\begin{array}{l}\text { Upper } \\
\text { Bound }\end{array}$ & Tolerance & VIF \\
\hline \multirow[t]{2}{*}{1} & (Constant) & 1.497 & 0.169 & & 8.859 & 0.000 & 1.146 & 1.847 & & \\
\hline & $\mathrm{X} 13$ & 0.393 & 0.050 & 0.861 & 7.939 & 0.000 & 0.291 & 0.496 & 1.000 & 1.000 \\
\hline \multirow[t]{3}{*}{2} & (Constant) & 1.015 & 0.128 & & 7.958 & 0.000 & 0.750 & 1.280 & & \\
\hline & $\mathrm{X} 13$ & 0.252 & 0.037 & 0.551 & 6.730 & 0.000 & 0.174 & 0.330 & 0.638 & 1.568 \\
\hline & X17 & 0.274 & 0.044 & 0.515 & 6.284 & 0.000 & 0.183 & 0.365 & 0.638 & 1.568 \\
\hline
\end{tabular}

Sumber : Hasil Olahan

Dari tabel diatas, didapatkan variabel penentu untuk persamaan regresi hubungan peran Tim Tender dengan tingkat keberhasilan untuk memenangkan tender. Variabel tersebut adalah $\mathrm{X}_{13}$ (Ketersediaan Sumber Daya Manusia) dan $\mathrm{X}_{17}$ (Kompetensi Perusahaan), sehingga persamaan regresi berdasarkan tabel diatas adalah : 


$$
Y=1,015+0,252 X_{13}+0,274 X_{17}
$$

dengan:

$\begin{array}{ll}Y & : \text { Tingkat Keberhasilan } \\ X_{13} & : \text { Ketersediaan Sumber Daya Manusia } \\ X_{17} & : \text { Kompetensi Perusahaan }\end{array}$

Hasil analisis regresi linier menyatakan bahwa tingkat keberhasilan Tim Tender dalam usaha meraih target nilai kontrak pada perusahaan jasa konstruksi khususnya kontraktor akan semakin besar apabila faktor-faktor yang mempengaruhi di bawah ini ditingkatkan, yaitu :

- Ketersediaan sumber daya manusia yang berkualitas dalam Tim Tender.

- Kompetensi perusahaan terhadap bisnis usaha jasa konstruksi.

Hal ini dapat diperkuat dan diperjelas dengan pernyataan dibawah ini:

a. Dalam usaha untuk bisa masuk ke dalam nominasi tiga besar dan dalam usaha memenangkan tender ketika kontraktor mengikuti suatu proses pelelangan, kompetensi perusahaan sangatlah berpengaruh. Menurut pendapat seorang pakar (IS), persyaratan dalam dokumen kualifikasi seringkali mempersyarat hal-hal yang berkaitan dengan kompetensi perusahaan dan bersifat menggugurkan, misalnya sertifikat manajemen mutu, pengalaman dan kemampuan kontraktor dalam menangani proyek sejenis, dan kualifikasi dan kompetensi sumber daya manusia untuk menangani suatu proyek. Menurut Park, William, R, 1979, salah satu penyebab kegagalan kontraktor dalam memenangkan proses tender adalah tidak berkompetennya perusahaan tersebut, karena ketika suatu kontraktor disebut kurang mempunyai kompetensi maka kontraktor tersebut kurang mempunyai kekuatan yang cukup, kapasitas, kualifikasi, dan manajemen untuk mengembangkannya. Kurangnya kompetensi pada kontraktor antara lain pada kemampuan manajerial atau kemampuan teknis, namun pengalaman menunjukkan bahwa ketidakmampuan secara manajerial lebih berbahaya daripada ketidakmampuan secara teknis.

b. Ketersediaan sumber daya manusia yang berkualitas dalam Tim Tender sangat mempengaruhi kinerja keberhasilan masuk dalam nominasi pelelangan dan dalam usaha memenangkan tender. Menurut pendapat seorang pakar (BS), personil dalam Tim Tender seharusnya mempunyai 
pendidikan dan pengalaman kerja khususnya mengenai pelaksanaan proyek dilapangan dengan baik sehingga asumsi-asumsi yang riil dan efisien dalam proses penyusunan penawaran harganya. Sedangkan menurut Hughes, Shawn W, 2004, suatu proyek dapat menjadi sukses jika diawali dengan proses perencanaan yang matang. Perencanaan proyek ini seharusnya dilakukan oleh personil-personil yang berkompeten, berkualitas, dan berpengalaman sehingga hasil semua asumsi pada saat proses perencanaan bisa diaplikasikan dilapangan. Proses perencanaan yang kurang baik seringkali terjadi dikarenakan personil yang melaksanakan tidak berkualitas dan belum terbiasa dengan permasalahan yang dihadapi.

\section{KESIMPULAN}

Berdasarkan hasil penelitian yang telah dilakukan yang selanjutnya dibahas dengan kajian literatur dan validasi ke pakar, maka dapat disimpulkan bahwa, terdapat pengaruh yang signifikan antara peran Tim Tender terhadap tingkat keberhasilan memenangkan tender dalam usaha untuk meraih target nilai kontrak khususnya untuk tender yang bersifat kompetitif. Beberapa faktor yang berpengaruh kuat tersebut adalah :

1. Kompetensi perusahaan terhadap bisnis usaha jasa konstruksi semakin ditingkatkan untuk meningkatkan daya saing perusahaan dengan kontraktor yang lain melalui penerapan sistem manajemen kualitas yang memadai yang diterapkan pada perusahaan sehingga semua proses dan produk-produk yang dihasilkan melalui proses itu mempunyai kualitas yang dapat diandalkan.

2. Ketersediaan sumber daya manusia yang berkualitas khususnya pada bagian perencanaan proyek lebih ditingkatkan melalui pengembangan dan pengelolaan sumber daya manusia yang berkesinambungan karena sumber daya manusia merupakan motor penggerak perusahaan sehingga sumber daya manusia kontraktor akan menjadi profesional, yaitu perpaduan antara kemampuan teknis yang tinggi dan kepribadian yang ideal.

3. Perencanaan strategi perusahaan secara korporat yang berkaitan dengan fungsi pemasaran dan fungsi perencanaan proyek lebih dikembangkan.

4. Kemampuan keuangan perusahaan untuk lebih ditingkatkan melalui peningkatan aspek manajemen keuangan yang lebih terorganisir dan terkendali agar keuangan perusahaan tidak mengalami kesulitan yang pada akhirnya bisa mengganggu kelangsungan usaha.

\section{DAFTAR PUSTAKA}

Asiyanto, Ir, MBA, IPM, “Construction Project Cost Management", Pradnya Paramita, 2005. 
Asiyanto, Ir, MBA, IPM, “Manajemen Produksi Untuk Jasa Konstruksi”, Pradnya Paramita, 2005.

Asiyanto, Ir, MBA, IPM, "Materi Kuliah - Manajemen Kontraktor", Program Pasca Sarjana Teknik Sipil Universitas Indonesia, 2006.

Chinowsky, Paul S., "Strategic Management In Engineering Organizations", Journal Of Management In Engineering, April 2001.

CV Novindo Pustaka Mandiri, "Keputusan Presiden Nomor 80 Tahun 2003 Tentang Pedoman Pelaksanaan Pengadaan Barang/Jasa Pemerintah", Jakarta 2006.

Dysert, Larry and Elliot, Bruce G., "The Estimate Review And Validation Process", Cost Engineering, January 2002.

Hegazy, Tarek and Moselhi, Osama, "Element Of Cost Estimation : A Survey in Canada and United States", Cost Engineering, May 1995.

Park, William R., P.E., "Construction Bidding For Profit”, John Wiley \& Sons, 1979.

Pembangunan Perumahan, PT, "Buku Referensi Untuk Kontraktor - Bangunan Gedung dan Sipil", PT Gramedia Pustaka Utama, 2003.

Sarwono, Jonathan, "Analisis Data Penelitian Menggunakan SPSS 13", Andi Yogyakarta, 2006.

Shash, Ali A, DR, “Competitive Bidding System”, Cost Engineering, February 1995.

Shash, Ali A, DR and Al-Khaldi, Zaitoun S., "The Production Of Accurate Construction Cost Estimates In Saudi Arabia", Cost Engineering, August 1992.

Shawn W Hughes; Donald D Tippett; Warren K Thomas., "Measuring Project Success in the Construction Industry", Engineering Management Journal, September 2004. 